\title{
Psychometric properties of the Thai Mental Health Literacy Scale in sixth-year medical students
}

Gobhathai Sittironnarit ( $\nabla$ gobhathai.kua@mahidol.edu )

Department of Psychiatry, Faculty of Medicine Siriraj Hospital, Mahidol University, Bangkok

\section{Rungsipohn Sripen}

Department of Psychiatry, Faculty of Medicine Siriraj Hospital, Mahidol University, Bangkok

\section{Sucheera Phatharayuttawat}

Department of Psychiatry, Faculty of Medicine Siriraj Hospital, Mahidol University, Bangkok

\section{Research Article}

Keywords: assessment, experience, help-seeking, medical externs, externship, professional, reliability, validity

Posted Date: February 23rd, 2021

DOl: https://doi.org/10.21203/rs.3.rs-155766/v1

License: (1) (1) This work is licensed under a Creative Commons Attribution 4.0 International License. Read Full License

Version of Record: A version of this preprint was published at Siriraj Medical Journal on February 1st, 2022. See the published version at https://doi.org/10.33192/Smj.2022.13. 


\section{Abstract}

Background: Mental health literacy reduces stigma and the risk of developing mental disorders along with increasing help-seeking behavior. The aim of this study was to translate and study both the psychometric properties of the Thai Mental Health Literacy Scale (TMHLS) and the mental health literacy in sixth-year Thai medical students of the Faculty of Medicine Siriraj Hospital, Bangkok.

Methods: Two-hundred and fifty participants were enrolled using the convenience sampling method. Descriptive statistics were used to analyze demographic data and mental health experiences. Inferential statistics were applied to compare sources of mental health experiences. The content validity and reliability by internal consistency of the TMHLS was analyzed by Index of item objective congruence (IOC) obtained from the examination of three experts in mental health field and Cronbach's Alpha, respectively.

Results: The TMHLS had good content validity (IOC=.67-1.0) and good reliability (Cronbach's alpha=.85). The participants' mean ( \pm S.D.) mental health literacy score was $123.09( \pm 11.55)$. Individuals who had a mental health professional as an intimate contact and individuals who had a history of seeking help from mental health professional(s) in person showed significantly higher mental health literacy than those who did not.

Conclusions: The TMHLS has good psychometric properties. Dynamic knowledge transfer and exchange with a close mental health professional should be applied to promote mental health literacy in medical students.

\section{Background}

Mental health problems have been increasing throughout the world [1], with young adults (aged 18-25 years) being the most affected group. At least, $30 \%$ of young adults have mental disorders while the remaining $70 \%$ are also at risk of developing mental disorders. Three-quarters of all psychiatric disorders have their onset during this period of a person's life [2]. Studies have found that people in this age group, especially university students reported higher levels of stress and mental health problems and had the lowest-tendency to engage in help-seeking behavior, due to poor mental health literacy [3-7].

Mental health literacy reduces stigma and the risk of developing mental disorders along with increasing help-seeking behavior [8]. People with high mental health literacy will be able to recognize, manage, and prevent mental health problems. On the other hand, people with low mental health literacy may not be able to appropriately manage and often end up with more serious complications which has a negative impact on them, society, and their country [9].

Presently, no proper, convenient, or time-efficient psychometric measurement is available in Thai. The aim of this study was to translate and study psychometric properties of the Thai mental health literacy scale (TMHLS). Sixth-year medical students (i.e. externs) from the Faculty of Medicine Siriraj Hospital in 
Bangkok, Thailand were chosen for three reasons. First, they were university students and young adults at risk of onset of mental disorder $[2,10,11]$. Second, literature review has shown that experiences of working with patients affects the ability to recognize and diagnose mental disorders $[12,13]$ which is a key structure of mental health literacy. These students had already experienced a four-week psychiatric rotation in their fifth-year of medical training. Last but not least, in the near future, these students will work as general practitioners (GP) and encounter patients with both physical and mental illnesses $[14,15$, 16].

\section{Method}

\subsection{Participants}

The number of participants in this study was determined by the Cochran formula [17], which is $n=P(1-P)$ $Z^{2} / E^{2}$. The confidence level was at 95 percent and the error of expected reliable validity was .05 . Twohundred and forty-six participants were the minimum required to follow the formula.

We expanded the sample size to 250 and enrolled sixth-year medical students (externs) who had registered for the first semester in academic year 2017 and voluntarily answered the questionnaire in this study by Sripen R. and a research assistant using the convenience sampling method on orientation day under the permission of the Deputy Dean of Undergraduate Education of Faculty of Medicine Siriraj Hospital, Mahidol University Bangkok, Thailand.

\subsection{Tools}

A demographic questionnaire was used to collect data from medical students including gender, age, and mental health experiences after a psychiatric rotation in their fifth-year; their exposure to media such as the internet, newspaper, and television; self-experience of mental disorder(s); having family members or friends with a mental illness; having a mental health professional such as a psychiatrist, psychiatric nurse, clinical psychologist, or counsellor as an intimate contact; history of seeking help from mental health professional(s) in person; and history of seeking help from mental health professional(s) for family members or friends. We also asked the participants about their mental illness if applicable.

\subsection{The translation of mental health literacy scale (MHLS)}

The mental health literacy scale (MHLS) was created by Matt O'Connor and Leanne Casey at Griffith University, Australia. It contains good internal consistency at .873 and test-retest reliability at .797 [18]. Permission to translate and use the MHLS was kindly granted by Matt O'Connor.

The MHLS was translated to Thai under the supervision of a professor of English language and literature. The index of item-objective congruence (IOC) was used to verify content validity by three mental health experts: one psychiatrist and one licensed clinical psychologist from the Department of Psychiatry, Faculty of Medicine Siriraj Hospital, and one professor who obtained a clinical psychologist license from the Faculty of Psychology, Chulalongkorn University. The Thai mental health literacy scale (TMHLS) was finally completed following expert opinion. 
The TMHLS is a self-reporting questionnaire with 35 items covering six attributes of mental health literacy: the ability to recognize a disorder, knowledge of where to seek information, knowledge of risk factors and causes, knowledge of self-treatment, knowledge of professional help available and attitudes that promote recognition or appropriate help-seeking behavior. The total score is the summation of all items. Therefore, the maximum score is 160 whereas the minimum score is 35 . A higher score means greater mental health literacy.

\subsection{Statistical analyses}

All statistical analyses were performed by SPSS version 23. Descriptive statistics were used to analyze frequency and percentage of gender, age, and mental health experiences. Inferential statistics were applied to compare the sources of mental health experiences which affected the participants' mental health literacy. The content validity and reliability by internal consistency of the Thai mental health literacy scales (TMHLS) was analyzed by the IOC and Cronbach's Alpha, respectively. (Fig. 1)

\section{Results}

\subsection{The sixth-year medical students}

Two-hundred and two of the 250 sixth-year medical students (externs) or $80.8 \%$ of the participants answered and returned the questionnaires.

The majority of respondents were female $(n=133 ; 65.8 \%)$ and the sample age range was between $22-24$ years $(M=23, S D=0.46)$. Psychiatric rotation in their fifth-year was the most popular source of their mental health experience $(n=190 ; 94.1 \%)$, followed by media exposure $(n=139 ; 68.8 \%)$, and having family members or friends with mental disorder(s) $(n=110 ; 54.5 \%)$. The other sources were their own experience of mental disorder(s) $(n=31 ; 15.3 \%)$, having intimate contact with a mental health professional $(n=29 ; 14.4 \%)$, history of seeking help from a mental health professional $(s)$ in person $(n=$ $19 ; 9.4 \%)$ and history of seeking help from mental health professional(s) for family members or friends $(n=16 ; 7.9 \%)$.

Thirteen out of 202 medical students had major depressive disorder (MDD) (6.4\%), the most common diagnoses among the samples. Other mental health problems of participants included panic disorder $(\mathrm{n}=$ 3; 1.5\%); adjustment disorder and attention deficit hyperactivity disorder (ADHD) in equal numbers $(n=2$; $1 \%)$; bipolar disorder as well as premenstrual dysphoric disorder (PMDD) and relationship problems in one participant respectively $(n=1 ; 0.5 \%)$. Eight participants $(4 \%)$ also reported unspecified mental health problems (Table 1). 
Table 1

Demographic data of the sixth-year medical students $(n=202)$

Attributes

\section{Response rates}

Sex Female

Male

Age (years) 22

23

24

$(M=23, S D=0.46$, Range $22-24$ years $)$

\section{Sources of mental health experiences}

(mutual items and answers reasonable)

- Fifth-year rotation (psychiatry)

- Self-experience of mental disorder(s)

- Having a mental health professional as an intimate contact

- History of seeking help from mental health professional(s) in person

- History of seeking help from mental health professional(s) for family members or friends
Frequency

(n)

202

133

69

22

158

22
34.2

10.9

78.2

10.9

(\%)

80.8

65.8

18.2$$
0.9
$$

- Media (internet/ newspaper/ television)

68.8

Types of mental illness

- Major depressive disorder (MDD)

- Panic disorder

3

- Adjustment disorder 2

- Attention deficit hyperactivity disorder (ADHD) 2

- Bipolar disorder 1

- Premenstrual dysphoric disorder (PMDD) 1 1

- Unspecified 


\subsection{The psychometric properties of the Thai mental health literacy scale (TMHLS)}

The first-round of content validity was .67 with nine of the 35 items (items number $2,3,5,6,7,8,15,20$ and 24$)$ defined as needing revision $(I O C>.05)$ (Table 2). After revision of the nine items, content validity in the second round increased to .85 . However, four of the nine items (items number 3, 5, 15 and 20) were still defined as needing revision (IOC > .05) (Table 3$)$. 
Table 2

The first-round of content validity of the Thai mental health literacy scale (TMHLS)

\begin{tabular}{|c|c|c|c|c|c|c|}
\hline \multirow[t]{2}{*}{ Items } & \multicolumn{3}{|c|}{ Score from experts } & \multirow[t]{2}{*}{ Total } & \multirow[t]{2}{*}{$10 C$} & \multirow[t]{2}{*}{ Results } \\
\hline & 1st & 2nd & 3rd & & & \\
\hline 1 & 0 & +1 & +1 & 2 & .67 & Useable \\
\hline 2 & -1 & +1 & +1 & 1 & .33 & Need for Revision \\
\hline 3 & 0 & 0 & +1 & 1 & .33 & Need for Revision \\
\hline 4 & 0 & +1 & +1 & 2 & .67 & Useable \\
\hline 5 & -1 & +1 & +1 & 1 & .33 & Need for Revision \\
\hline 6 & 0 & 0 & 0 & 0 & 0 & Need for Revision \\
\hline 7 & 0 & 0 & +1 & 1 & .33 & Need for Revision \\
\hline 8 & -1 & 0 & 0 & -1 & -.33 & Need for Revision \\
\hline 9 & +1 & +1 & +1 & 3 & 1 & Useable \\
\hline 10 & +1 & +1 & +1 & 3 & 1 & Useable \\
\hline 11 & +1 & +1 & 0 & 2 & .67 & Useable \\
\hline 12 & +1 & +1 & +1 & 3 & 1 & Useable \\
\hline 13 & +1 & +1 & 0 & 2 & .67 & Useable \\
\hline 14 & +1 & +1 & +1 & 3 & 1 & Useable \\
\hline 15 & 0 & -1 & +1 & 0 & 0 & Need for Revision \\
\hline 16 & +1 & +1 & +1 & 3 & 1 & Useable \\
\hline 17 & +1 & +1 & +1 & 3 & 1 & Useable \\
\hline 18 & 0 & +1 & +1 & 2 & .67 & Useable \\
\hline 19 & +1 & +1 & +1 & 3 & 1 & Useable \\
\hline 20 & 0 & -1 & +1 & 0 & 0 & Need for Revision \\
\hline 21 & +1 & +1 & +1 & 3 & 1 & Useable \\
\hline 22 & +1 & +1 & +1 & 3 & 1 & Useable \\
\hline 23 & 0 & +1 & +1 & 2 & .67 & Useable \\
\hline 24 & -1 & -1 & -1 & -3 & -1 & Need for Revision \\
\hline 25 & +1 & +1 & +1 & 3 & 1 & Useable \\
\hline
\end{tabular}




\begin{tabular}{|lllllll|}
\hline \multirow{2}{*}{ Items } & \multicolumn{2}{c}{ Score from experts } & Total & IOC & Results \\
\cline { 2 - 3 } & 1st & 2nd & 3rd & & & \\
\cline { 1 - 2 } 26 & +1 & +1 & +1 & 3 & 1 & Useable \\
\hline 27 & +1 & +1 & +1 & 3 & 1 & Useable \\
\hline 28 & +1 & +1 & 0 & 2 & .67 & Useable \\
\hline 30 & +1 & +1 & +1 & 3 & 1 & Useable \\
\hline 31 & +1 & +1 & +1 & 3 & 1 & Useable \\
\hline 32 & +1 & +1 & +1 & 3 & 1 & Useable \\
\hline 33 & +1 & +1 & +1 & 3 & 1 & Useable \\
\hline 34 & +1 & +1 & +1 & 3 & 1 & Useable \\
\hline 35 & +1 & +1 & +1 & 3 & 1 & Useable \\
\hline Total & & & & & .67 & Useable \\
\hline
\end{tabular}


Table 3

The second-round of content validity of the Thai mental health literacy scale (TMHLS)

\begin{tabular}{|c|c|c|c|c|c|c|}
\hline \multirow[t]{2}{*}{ Items } & \multicolumn{3}{|c|}{ Score from experts } & \multirow[t]{2}{*}{ Total } & \multirow[t]{2}{*}{ IOC } & \multirow[t]{2}{*}{ Results } \\
\hline & 1st & 2nd & 3rd & & & \\
\hline 1 & 0 & +1 & +1 & 2 & .67 & Useable \\
\hline 2 & +1 & +1 & +1 & 3 & 1 & Useable \\
\hline 3 & +1 & +1 & -1 & 1 & .33 & Need for Revision \\
\hline 4 & 0 & +1 & +1 & 2 & .67 & Useable \\
\hline 5 & +1 & +1 & -1 & 1 & .33 & Need for Revision \\
\hline 6 & +1 & +1 & +1 & 3 & 1 & Useable \\
\hline 7 & +1 & +1 & +1 & 3 & 1 & Useable \\
\hline 8 & +1 & +1 & +1 & 3 & 1 & Useable \\
\hline 9 & +1 & +1 & +1 & 3 & 1 & Useable \\
\hline 10 & +1 & +1 & +1 & 3 & 1 & Useable \\
\hline 11 & +1 & +1 & 0 & 2 & .67 & Useable \\
\hline 12 & +1 & +1 & +1 & 3 & 1 & Useable \\
\hline 13 & +1 & +1 & 0 & 2 & .67 & Useable \\
\hline 14 & +1 & +1 & +1 & 3 & 1 & Useable \\
\hline 15 & +1 & +1 & -1 & 1 & .33 & Need for Revision \\
\hline 16 & +1 & +1 & +1 & 3 & 1 & Useable \\
\hline 17 & +1 & +1 & +1 & 3 & 1 & Useable \\
\hline 18 & 0 & +1 & +1 & 2 & .67 & Useable \\
\hline 19 & +1 & +1 & +1 & 3 & 1 & Useable \\
\hline 20 & +1 & +1 & -1 & 1 & .33 & Need for Revision \\
\hline 21 & +1 & +1 & +1 & 3 & 1 & Useable \\
\hline 22 & +1 & +1 & +1 & 3 & 1 & Useable \\
\hline 23 & 0 & +1 & +1 & 2 & .67 & Useable \\
\hline 24 & +1 & +1 & +1 & 3 & 1 & Useable \\
\hline 25 & +1 & +1 & +1 & 3 & 1 & Useable \\
\hline
\end{tabular}




\begin{tabular}{|lllllll|}
\hline Items & \multicolumn{3}{c}{ Score from experts } & Total & IOC & Results \\
\cline { 2 - 4 } & 1st & 2nd & 3rd & & & \\
\hline 26 & +1 & +1 & +1 & 3 & 1 & Useable \\
\hline 27 & +1 & +1 & +1 & 3 & 1 & Useable \\
\hline 28 & +1 & +1 & 0 & 2 & .67 & Useable \\
\hline 29 & +1 & +1 & +1 & 3 & 1 & Useable \\
\hline 30 & +1 & +1 & +1 & 3 & 1 & Useable \\
\hline 31 & +1 & +1 & +1 & 3 & 1 & Useable \\
\hline 32 & +1 & +1 & +1 & 3 & 1 & Useable \\
\hline 33 & +1 & +1 & +1 & 3 & 1 & Useable \\
\hline 34 & +1 & +1 & +1 & 3 & 1 & Useable \\
\hline 35 & +1 & +1 & +1 & 3 & 1 & Useable \\
\hline Total & & & & & .85 & Useable \\
\hline
\end{tabular}

The Cronbach's Alpha measurement was .85 which is considered a good criterion. Nevertheless, the reliability coefficients of all 35 items from the measurement, showed that there were six items (items number $9,10,11,12,15$ and 20) which did not meet the criterion (CITC <.20). The Cronbach's Alpha after removing items that did not meet the criterion was .872 which was in the same interval as the prior one. Thus, all items that did not meet the criterion were still preserved (Table 4). 
Table 4

Reliability coefficients of all 35 Items from the Thai mental health literacy scale (TMHLS)

\begin{tabular}{|c|c|c|c|c|}
\hline Items & $\begin{array}{l}\text { Scale Mean if } \\
\text { Item Deleted }\end{array}$ & $\begin{array}{l}\text { Scale Variance if } \\
\text { Item Deleted }\end{array}$ & $\begin{array}{l}\text { Corrected Item-Total } \\
\text { Correlation }\end{array}$ & $\begin{array}{l}\text { Cronbach's Alpha if } \\
\text { Item Deleted }\end{array}$ \\
\hline 1 & 120.0050 & 127.146 & .388 & .847 \\
\hline 2 & 120.1608 & 126.206 & .440 & .845 \\
\hline 3 & 119.7186 & 127.203 & .444 & .846 \\
\hline 4 & 120.0101 & 125.677 & .442 & .845 \\
\hline 5 & 119.6734 & 125.160 & .509 & .844 \\
\hline 6 & 120.0151 & 127.096 & .339 & .848 \\
\hline 7 & 119.8442 & 126.263 & .402 & .846 \\
\hline 8 & 119.6482 & 124.320 & .544 & .843 \\
\hline 9 & 120.1709 & 132.405 & $.124^{\star \star}$ & .853 \\
\hline 10 & 120.4121 & 136.213 & $-.122^{\star \star}$ & .857 \\
\hline 11 & 119.9447 & 133.113 & $.089 * \star$ & .853 \\
\hline 12 & 120.6783 & 133.586 & $.028 * \star$ & .856 \\
\hline 13 & 119.9146 & 130.887 & .223 & .850 \\
\hline 14 & 119.6131 & 128.370 & .394 & .847 \\
\hline 15 & 120.3568 & 131.443 & $.140 * \star$ & .853 \\
\hline 16 & 119.1005 & 129.444 & .318 & .848 \\
\hline 17 & 119.1256 & 129.878 & .295 & .849 \\
\hline 18 & 118.9447 & 129.578 & .292 & .849 \\
\hline 19 & 118.8543 & 129.085 & .399 & .847 \\
\hline 20 & 120.4472 & 131.945 & $.077 * \star$ & .857 \\
\hline 21 & 119.2563 & 125.616 & .367 & .847 \\
\hline 22 & 118.9095 & 126.770 & .384 & .847 \\
\hline 23 & 119.1859 & 126.657 & .413 & .846 \\
\hline
\end{tabular}

**Items that have corrected item-total correlation less than .2 are not pass the criterion. 


\begin{tabular}{|lllll|}
\hline Items & $\begin{array}{l}\text { Scale Mean if } \\
\text { Item Deleted }\end{array}$ & $\begin{array}{l}\text { Scale Variance if } \\
\text { Item Deleted }\end{array}$ & $\begin{array}{l}\text { Corrected Item-Total } \\
\text { Correlation }\end{array}$ & $\begin{array}{l}\text { Cronbach's Alpha if } \\
\text { Item Deleted }\end{array}$ \\
\hline 24 & 118.9548 & 124.649 & .492 & .844 \\
\hline 25 & 119.3920 & 129.179 & .254 & .850 \\
\hline 26 & 118.7286 & 126.936 & .420 & .846 \\
\hline 27 & 118.7337 & 127.762 & .414 & .846 \\
\hline 28 & 118.6734 & 128.504 & .374 & .847 \\
\hline 29 & 120.4573 & 125.886 & .411 & .846 \\
\hline 30 & 119.7688 & 125.360 & .461 & .845 \\
\hline 31 & 119.3618 & 123.444 & .572 & .842 \\
\hline 32 & 119.5879 & 124.233 & .494 & .844 \\
\hline 33 & 120.4874 & 124.776 & .414 & .846 \\
\hline 34 & 120.0050 & 124.601 & .401 & .846 \\
\hline 35 & 119.6784 & 124.957 & .454 & .845 \\
\hline$* *$ Items that have corrected item-total correlation less than .2 are not pass the criterion.
\end{tabular}

\subsection{The mental health literacy in sixth-year medical students}

The mean score of the mental health literacy of sixth-year medical students was 123.09 (S.D. \pm 11.55 , $95 \% \mathrm{Cl}=121.49-124.69)$. The maximum score was 151 from a total score of 160 , whereas the minimum was 81 with the lowest possible being 35 .

After multiple comparisons of mental health literacy experiences of sixth-year medical students, having intimate contact with a mental health professional and a history of seeking help from a mental health professional(s) in person significantly correlated with the students' mental health literacy score. The mental health literacy of individuals who had intimate contact with a mental health professional was significantly higher than those who did not (mean \pm SD was $127.41 \pm 13.96$ and $122.37 \pm 10.99$, respectively; $t(200)=2.196, p<.05$ ). The magnitude of the difference in the means (mean different $=5.04$, $95 \% \mathrm{Cl}=.51-9.57)$ was small $(\mathrm{d}=.40)$. Likewise, mental health literacy of individuals who had a history of seeking help from mental health professional(s) in person was higher than those who did not (mean \pm SD was $128.84 \pm 10.25$ and $122.50 \pm 11.55$, respectively; $t(200)=2.302, p<.05$.). The magnitude of the difference in the means (mean different $=6.34,95 \% \mathrm{Cl}=.90$ - 11.78) was medium ( $d=.58)$ (Table 5). 
Table 5

The comparison of mental health literacy by mental health experiences

Mental health experiences

Media (internet/ newspaper/ television)

have

not have

Having family members or friends with a mental illness

have

not have

Self-experience of mental disorder(s)

have

not have

Having a mental health professional as an intimate contact

29

31

126.16

10.13

$\begin{array}{lll}171 & 122.54 & 11.74\end{array}$

S.D. $\quad t$

p

$\begin{array}{lll}63 & 121.14 & 10.49\end{array}$

$\begin{array}{lll}92 & 122.22 & 11.28\end{array}$

have

not have

$\begin{array}{lll}173 & 122.37 & 10.99\end{array}$

\section{History of seeking help from mental health}

professional(s) in person

have

not have

History of seeking help from mental health

professional(s) for family members or friends

have

not have
$19128.8410 .25 \quad 2.302^{*}$

$183 \quad 122.50 \quad 11.55$

$\begin{array}{lllllll}\text { have } & 16 & 124.94 & 10.85 & .664 & .507 \\ \text { not have } & 186 & 122.94 & 11.63 & & \end{array}$

$* p<.05$

\subsection{Questionnaire comments}

The questionnaire comments found that of the 202 participants, $5.9 \%$ reported that the questions were too comprehensive and needed to be defined clearly; $3 \%$ stated that the questions were too long; $1 \%$ said that questions about mental health experiences were not clear and that a separate version of the mental 
health literacy questionnaire for medical students and the general population was needed due to the complicated questions; $0.5 \%$ stated that the questions were theoretical and may not reflect true literacy as more questions about attitude were required; the questionnaire contained too many negative questions and the text "no and disagree" should be emphasized. Meanwhile, $0.5 \%$ also reported that the questionnaire form made it easy to answer and the questions were crystal clear.

\section{Discussion}

\subsection{The sixth-year medical students}

The most common mental disorders among sixth-year medical students (externs) in this study were major depressive disorder (MDD) and panic disorder which is in line with a previous Thai study that reported adjustment disorder, major depressive disorders, and dysthymia as the most common diagnoses of medical students who utilized the counselling unit of the Faculty of Medicine Siraj Hospital [19]. This was similar to a Malaysian study that found anxiety and depression to be common in medical students who attended a private university [20]. These outcomes were also supported by a Chinese meta-analysis study that showed depression, anxiety, suicidal ideation and eating disorders as the major contributors of mental health problems in medical students [21].

\subsection{The Psychometric properties of the Thai mental health literacy scale (TMHLS)}

The Thai mental health literacy scale has good validity and reliability. The content validity by the IOC in this study was between $.67-1.00$ and the reliability from Cronbach's Alpha was .851 .

Owing to some language deviation in translation of the TMHLS, the validity of the scale was tested two times by three experts in the mental health field. The IOC in the second-round was increased from .67 to .85 and only four out of nine items (items number $3,5,15$ and 20 ) needed to be revised (IOC > .05). According to a prior study, not all measurements can assess all attributions of mental health literacy and suggested that some items needed to be removed [18]. In the end, all 35 items were used in the scale.

The Cronbach's Alpha of the TMHLS was .851 which is considered good for the reliability of testing. However, six items (items number 9, 10,11, 12, 15 and 20) of the scale did not meet the criterion (CITC $<.20)$. The Cronbach's Alpha after removing items that did not meet the criterion was slightly different from the Cronbach's Alpha when all 35 items were tested for. These six items remained in the scale for the same reasons as the previous study that found the measurement cannot assess all attributes of mental health literacy when some of the items needed to be removed [18]. Therefore, these six items which did not meet the criterion were statically persevered.

\subsection{The mental health literacy in sixth-year medical students}

The mental health literacy of sixth-year medical students in our work was in line with a prior British study [13]. Our score was marginally lower than that of an Australian study exploring mental health literacy in first-year university students [18]. This may reveal differences in mental health literacy between developing and developed countries. A previous Thai study showed no proficient way to differentiate 
between anxiety disorders from depressive disorders in one third of local village health workers and noted that acknowledgement of mental health literacy was required [22]. Additional supporting evidence was provided by a South African study that reported about mental health literacy and urged for mental health education of primary healthcare professionals in developing countries [23]. Moreover, language deviance and questionnaire format may also be responsible for the different results (see more information on "the questionnaire comments" topic).

Our participants had already gained mental health experience by their fifth-year of medical training and these practices may have affected their mental health literacy. Previous works also showed higher mental health literacy in individuals who encountered mental health problems than the individuals who did not $[12,24]$. The more exposure someone has, the more mentally health literate they are [12].

Consistent with a previous study [18], the mental health literacy of individuals who had a history of seeking help from mental health professional(s) in person was higher than those who did not (mean \pm SD was $128.84 \pm 10.25$ and $122.50 \pm 11.55$, respectively; $t(200)=2.302, p<.05)$. Dynamic knowledge transfer and exchange with a close mental health professional, like in family businesses [25], could also be a reason for higher mental health literacy of individuals who had a mental health professional as an intimate partner than those who did not (mean \pm SD was $127.41 \pm 13.96$ and $122.37 \pm 10.99$, respectively; $t(200)=2.196, p<.05)$.

\subsection{The questionnaire comments}

The main concern about the questionnaire was the complexity and clarity of the questions, however, the items that should be allocated were not mentioned in the notes. Basically, the Thai mental health literacy Scale (TMHLS) aims to assess general, not specific mental health literacy. According to the comments, students advised for a separate version of the mental health literacy assessment tool for medical students and the general population as evidence from a previous study, which is the original version of the mental health literacy scale [18], detailed that the measurement can be used to assess mental health literacy in assorted populations. Moreover, although some participants described the questionnaire as easy and clear to answer, an equal number asked for the questionnaire to highlight the text "no and disagree" and expressed concern that the form was overly theoretical and may not reflect accurate mental health literacy. They requested more questions about attitude to be included and sought to reduce excessive negative questions. As this work was intended to translate and study the psychometric properties of the TMHLS, we did not revise the original questions. A clearer definition of the mental health experience and who is an intimate person, i.e. parents, siblings or significant other, along with emphasizing the text with "no and disagree" should be considered in a further study.

\subsection{Limitations}

As we used convenience sampling in this study, an inherent bias could not be avoided. Our participants were not chosen at random. Thus, the results cannot legitimize any generalizations. Since we used Cronbach's Alpha for reliability testing of the Thai mental health literacy scale (TMHLS), the interitem covariance and the measurement assumptions error could be considered as the Alpha value cannot be 
equivalent with the reliability of the test score [26]. Cultural and linguistic context in the translation process may also have affected the TMHLS. Information and recall bias may have been present in this observational descriptive cross-sectional study. A prospective cohort study with semi-structured interviews for medical students in different academic years is obligatory.

\section{Conclusion}

Of the 202 sixth-year medical students, majority was female aged $22-24$ years. Approximately $6 \%$ of them had major depression. Psychiatric rotation was the most popular source of their mental health experience. The Thai mental health literacy scale (TMHLS) had good content validity $(I O C=.67-1.0)$ and good reliability (Cronbach's alpha $=.85$ ). From the lowest score of 35 to the highest of 160 , in which a higher score meant greater mental health literacy, the participants' mean ( \pm S.D.) mental health literacy score was 123.09 ( \pm 11.55$)$. Individuals who had a mental health professional as an intimate contact and individuals who had a history of seeking help from mental health professional(s) in person showed significantly higher mental health literacy than those who did not.

\section{Declarations}

\section{Ethics approval and consent to participate}

All procedures performed in studies involving human participants were in accordance with the ethical standards of the institutional and/or national research committee and with the 1964 Helsinki declaration and its later amendments or comparable ethical standards. This study was approved by Siriraj Institutional Review Board of Faculty of Medicine Siriraj Hospital, Mahidol University; COA no. Si203/2017; protocol number 127/2560 (EC3). The Mental Health Literacy Scale (MHLS) was kindly granted permission by the research team of Griffith University (Matt O'Connor \& Leanne Casey). Written informed consent was obtained from all individual participants included in the study.

\section{Consent for publication}

Not applicable.

\section{Availability of data and materials}

The datasets used and/or analysed during the current study are available from the corresponding author on reasonable request.

\section{Competing interests}

The authors declare that they have no competing interests

\section{Funding}


This research was funded by Siriraj Graduate Scholarship, Faculty of Medicine Siriraj Hospital, Mahidol University.

\section{Authors' contributions}

GS designed and coordinated the study, analyzed data and wrote the paper. RS co-designed the study, collected and analyzed data, helped to write and reviewed drafts of the paper. SP co-designed the study, help to analyzed data and reviewed drafts of the paper.

\section{Acknowledgements}

We gratefully acknowledge Matt O'Connor, Ph.D. and Leanne Casey, Ph.D. from Griffith University, Australia for their kind permission to allow us to use their scale in this work; the Postgraduate Education Division and Deputy Dean of Undergraduate Education of Faculty of Medicine Siriraj Hospital, Thailand for the scholarship and thoughtful permission to collect data, correspondingly. We also thank Boonjira Thungsuk, M.A. (English) and all expert validators: Tikumporn Hosiri, M.D., FRCPsychT; Panida Yomaboot, Ph.D. and Kullaya Pisitsungkagarn, Ph.D. for their superb suggestions about the Thai mental health literacy scale (TMHLS). Special thanks to Tuangsit Sittironnarit, M.S. for his great support. And last but not least, we thank all the participants in this study for their contribution.

\section{References}

1. GBD 2017 Disease and Injury Incidence and Prevalence Collaborators. Global, regional, and national incidence, prevalence, and years lived with disability for 354 diseases and injuries for 195 countries and territories, 1990-2017: a systematic analysis for the Global Burden of Disease Study 2017. The Lancet. 2018;392:1789-1858. doi: https://doi.org/10.1016/S0140-6736(18)32279-7.

2. Lê-Scherban F, Brenner AB, Schoeni RF. Childhood family wealth and mental health in a national cohort of young adults. SSM - Population Health. 2016;2:798-806. doi: 10.1016/j.ssmph.2016.10.008.

3. Stallman MH. Psychological distress in university students: a comparison with general population data. Australian Psychologist. 2010;45(4):249-257. doi: https://doi.org/10.1080/00050067.2010.482109.

4. Smith LC, Shochet IM. The impact of mental health literacy on help-seeking Intentions: results of a pilot study with first year psychology students. International Journal of Mental Health Promotion. 2011;13(2): 14-20.

5. Gulliver A, Griffiths MK, Helen C. Perceived barriers and facilitators to mental health help-seeking in young people: a systematic review. BMC Psychiatry. 2010;10(113):1-9. doi: https://doi.org/10.1186/1471-244X-10-113.

6. Hom MA, Stanley IH, Joiner TE. Evaluating factors and interventions that influence help-seeking and mental health service utilization among suicidal individuals: A review of the literature. Clinical Psychology Review. 2015;40:28-39. doi: 1016/j.cpr.2015.05.006. 
7. Rickwood JD, Deane PF, Coralie WJ. When and how do young people seek professional help for mental health problems? MJA. 2007;187(7):35-39. doi: 5694/j.1326-5377.2007.tb01334.x.

8. Wei Y, McGrath P, Hayden J, Kutcher S. Measurement properties of tools measuring mental health knowledge: a systematic review. BMC Psychiatry. 2016;16(297):2-16. doi:10.1186/s12888-016-10125 .

9. Marcus M, Westra H. Mental Health Literacy in Canadian Young Adults: Results of a National Survey. Canadian Journal of Community Mental Health. 2012;1(1-15). doi: https://doi.org/10.7870/cjcmh2012-0002.

10. Gentile JP, Roman B. Medical student mental health services: psychiatrists treating medical students. Psychiatry (Edgmont). 2009;6(5):38-45. PMID:

11. Jafari N, Loghmani A, Montazeri A. Mental health of medical students in different levels of training. International Journal of Preventive Medicine. 2012;3(1):S107-S112. PMID:

12. Cheslock PA. Assessing mental health literacy of first- and third-year medical students: knowledge and beliefs about mental disorders. Doctoral dissertation. Philadelphia College; 2005.

13. Marwood MR, Hearn JH. Evaluating mental health literacy in medical students in the United Kingdom. The Journal of Mental Health Training Education and Practice. 2019;14(5):339-347. doi: https://doi.org/10.1108/JMHTEP-01-2019-0001.

14. Culpepper $\mathrm{L}$. The role of primary care clinicians in diagnosing and treating bipolar disorder. Primary Care Companion to The Journal of Clinical Psychiatry. 2010;12(1):4-9. doi: http://doi.org/10.4088/PCC.9064su1c.01.

15. Toft T, Fink P, Oernboel E, Christensen K, Frostholm L, Olesen F. Mental disorders in primary care: Prevalence and co-morbidity among disorders. Results from the Functional Illness in Primary care (FIP) study. Psychological Medicine. 2005;35(8):1175-1184. doi: 1017/s0033291705004459.

16. Wittchen HU, Mühlig S, Beesdo K. Mental disorders in primary care. Dialogues in Clinical Neuroscience. 2003;5(2):115-128. PMID:

17. Cochran WG. Sampling techniques, 3rd ed. New York: John Wiley \& Sons; 1977.

18. O'Connor M, Casey L. The Mental Health Literacy Scale (MHLS): A new scale-based measure of mental health literacy. Psychiatry Research. 2015;229 (1-2):511-516. doi: 1016/j.psychres.2015.05.064.

19. Ketumarn P, Sitdhiraksa N, Sittironnarit G, Limsricharoen K, Pukrittayakamee P, Wannarit K. Mental health problems of medical students retired from the Faculty of Medicine, Siriraj Hospital, 1982-2007. J Psychiatr Assoc Thailand. 2013;58(3):271-282.

20. Saravanan C, Wilks R. Medical students' experience of and reaction to stress: the role of depression and anxiety. The Scientific World Journal. 2014;1-8. doi: http://dx.doi.org/10.1155/2014/737382

21. Zeng W, Chen R, Wang X, Zhang Q, Deng W. Prevalence of mental health problems among medical students in China. Medicine. 2019;98:18. doi: 10.1097/MD.0000000000015337. 
22. Kaewprom C, Yuthavisut S, Pratoom L, Boontum A. Mental health literacy among village health workers: a case study of two sub-districts in Kloong, Chantaburi. Journal of health science research. 2014;8(1):10-16.

23. Ganasen KA, Parker S, Hugo CJ, Stein DJ, Emsley RA, Seedat S. Mental health literacy: focus on developing countries. Afr J Psychiatry (Johannesbg). 2008;11(1):23-28. doi: 4314/ajpsy.v11i1.30251.

24. Kermode M, Bowen K, Arole S, Pathare S, Jorm AF. Attitudes to people with mental disorders: a mental health literacy survey in a rural area of Maharashtra, India. Soc Psychiat Epidemiol. 2009;44:1087-1096. doi: 10.1007/s00127-009-0031-7.

25. Letonja M, Duh M. Knowledge transfer in family businesses and its effects on the innovativeness of the next family generation. Knowledge Management Research \& Practice. 2016;14:2:213-224. doi: 1057/kmrp.2015.25.

26. Sijtsma K. On the use, the misuse, and the very limited usefulness of Cronbach's Alpha. Psychometrika. 2009;74(1):107-120. doi: 1007/s11336-008-9101-0.

\section{Figures}




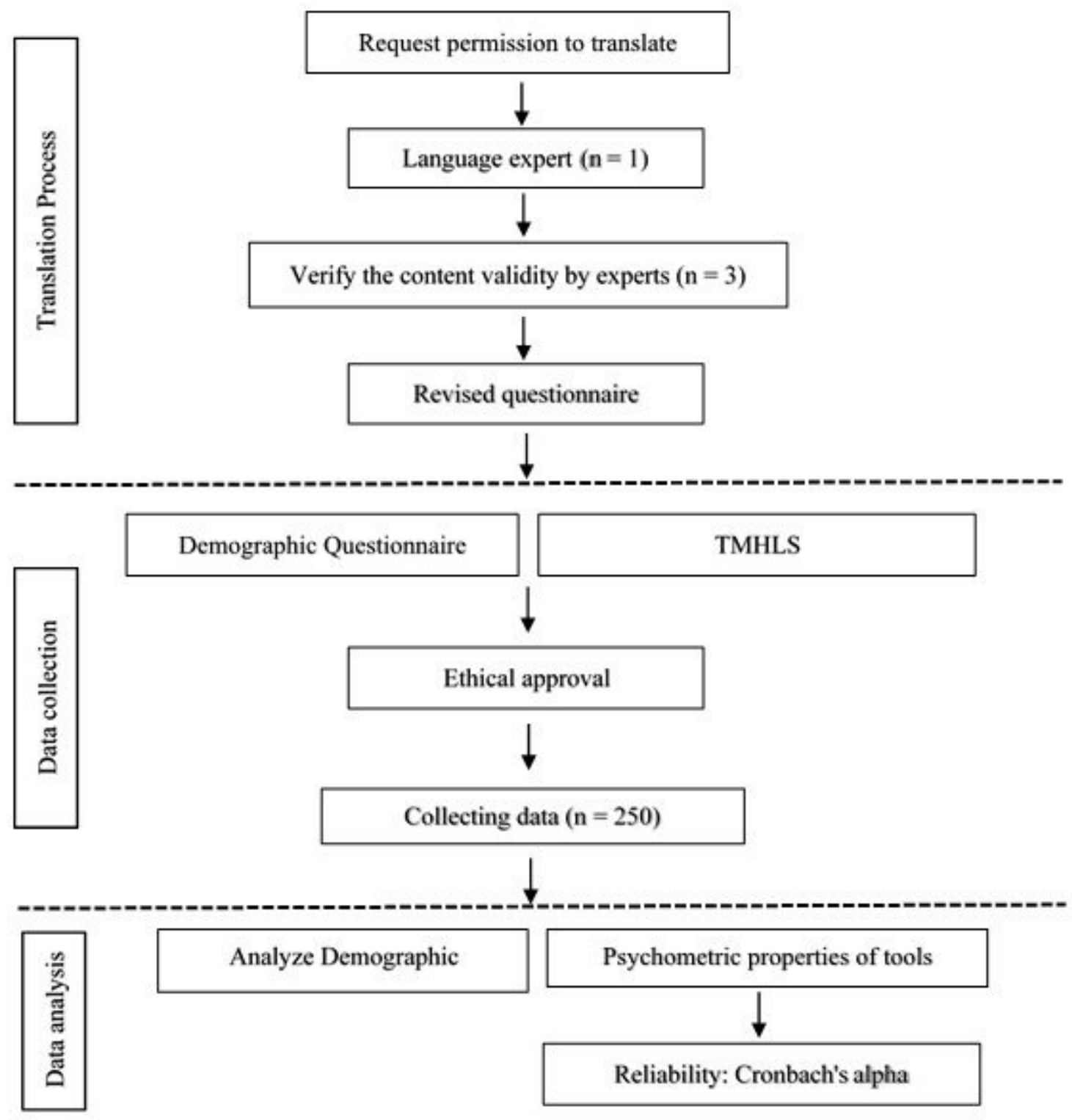

Figure 1

Summary of the research process 